\title{
SOBRE EL ARQUITECTO JUAN DE SEGARRA, TENIENTE DE MAESTRO MAYOR DEL CONCEJO HISPALENSE
}

\author{
POR FERNANDO CRUZ ISIDORO
}

De este avezado arquitecto, que desarrolló una amplia actividad en la Sevilla de la primera mitad del siglo XVII, se conocen múltiples datos sobre su vida y obra, publicados de forma dispersa en su mayoría por Celestino López Martínez como repertorios documentales, careciendo de una monografía actualizada, ya que los comentarios sobre su personalidad parten de lo apuntado y de las notas históricas que ese autor insertó el $1^{\circ}$ de agosto de 1918 en el periódico El Liberal, en el que confundiendo algunos datos, entremezcló las noticias biográficas de Juan de Segarra padre y las de su hijo, de igual nombre y profesión, con lo que ese error se ha mantenido hasta nuestros días. Hemos pretendido recoger y analizar esos datos, incidiendo en tal distinción, enumerar brevemente los profesionales, y ampliarlos con la labor del padre como colaborador y sustituto del maestro mayor Pedro Sánchez Falconete en 1648, en sus cargos de arquitecto de la Catedral, Ayuntamiento, y Lonja de Mercaderes.

\section{NOTICIAS BIOGRAFICAS}

Si analizamos los diferentes documentos que López Martínez trancribe, se advierte como algunos relativos a su biografía no pueden aludir a una misma persona. Así, si recoge que en julio de 1626 su hija Teresa, fruto de su matrimonio con María de Ribera, fué apadrinada por el imaginero Martínez Montañés, y que en abril de 1629 dota a otra hija, de igual nombre que su madre, para entrar como monja en el convento sevillano de la Concepción, no puede ser el mismo Juan de Segarra que en abril de 1634, en una solicitud de aceptación de limpieza de sangre declara, "soy soltero y por casar, y no tengo palabra de casamiento", y por hermanas 
cita a Teresa, Ana María, Josefa y Angela de Ribera. La clave para resolver la confusión la encontramos en el inicio de ese expediente de averiguación, de octubre de 1631, en el que ese individuo manifiesta su lugar de nacimiento y genealogía, y como sus padres, vivos, eran Juan de Segarra y María de Ribera. Por tanto, de aquí parte el equívoco al confundir a ambos, y asignar esas noticias biográficas del hijo a la producción artística identificada de un Juan de Segarra que no puede ser sino el padre, el arquitecto que tratamos, ya que queda claro que los documentos anteriores corresponden a éste y a su esposa, y por otros datos, entre ellos la antigüedad de algunos y el hecho de que cuando solicitó la plaza de maestro mayor de la Ciudad, en 1635, expuso toda su obra realizada desde 1621, como el citado convento de la Concepción donde profesó su hija, nos permiten identificar con el progenitor el grueso de la producción conocida, quedando siempre la duda de lo realizado por el hijo al titularse de igual forma en esos dos documentos sobre su ascendencia, como maestro de albañilería, arquitecto y alcalde alarife, ya que son los únicos que de forma clara aluden a su personalidad '.

Siguiendo tal hipótesis hay que desbaratar su biografía tradicional y reelaborarla, y así, el arquitecto Juan de Segarra fué hijo de Juanes de Segarra y de Gracia de Juan Manforena, y nació en Huici, en el valle de Larraúm, del partido judicial de Pamplona, en las montañas del reino de Navarra, en donde casó con María de Ribera, natural de Gorriti, del mismo valle, cuyos padres fueron Esteban de Orella y María de Loyaeta, todos descendientes de cristianos viejos y, al parecer, de sangre hidalga, como tenían a gala manifestar los de esa zona. De su matrimonio nacieron varios hijos, entre ellos Juan, al parecer el primogénito, que por seguir la tradición y línea directa del padre y abuelo adoptó su apellido, por tanto llamado Juan de Segarra, aunque familiarmente identificado como "el Mozo", según se cita, cuyos datos biográficos son los que hasta ahora erróneamente se venían manteniendo para el autor de las obras conocidas, que vino al mundo en la pequeña villa de Icazteguieta, que con Baliarraín y Orendain forman actualmente el municipio de Iruerrieta, : a donde se habían trasladado Juan de Segarra y María de Ribera, y donde pasó su infancia hasta los doce años, momento en que deciden emprender una nueva vida en la distante Sevilla, animados por las buenas espectativas de trabajo que podía ofrecer a un experto constructor como el cabeza de familia, que terminó de formarse en la rama de la albañilería al contacto con la estética tardomanierista que se vivía en la región en los primeros años del siglo XVII, decantando a su hijo "el Mozo" por la misma actividad.

Sus hijas eligieron el apellido de la madre, y así aparecen como Josefa, Teresa, Ana María y Angela de Ribera. Teresa nació en Sevilla, bautizada el domingo 12 de julio de 1626 en la parroquial del Salvador, con un padrino de

1. LOPEZ MARTINEZ, Celestino: Testimonios para la biografia de Juan Martínez Montañés. "Documentos para la $\mathrm{H}^{\mathrm{a}}$ del Arte en Andalucía", T. I, Sevilla, 1927, p. 222. Arquitectos, escultores $y$ pintores vecinos de Sevilla. Sevilla, 1928, pp. 187-188. 
lujo, el genial Martínez Montañés ${ }^{2}$. A María, para que pudiese ingresar como monja en el convento de la Pura y Limpia Concepción de María, edificio que levantó con sus manos, el 25 de abril de 1629 le otorgó carta dotal prometiendo 1.000 ducados el día que hiciere solemne profesión, y en el entretanto, 15.000 maravedíes y un cahiz de trigo al año para su sustento.

Su hijo Juan, para dejar constancia del origen familiar, el 25 de octubre de 1631 compareció ante el alcalde del lugar de Lecumberri, en el valle solariego de Larraum, en Navarra, testificando los datos de sus progenitores y los propios que hemos comentado, y como su familia era "limpia de toda raza y mácula de moros y judíos, y de los nuevamente convertidos a nuestra santa fe católica, y de otra mala secta y penitenciados y castigados por el Santo Oficio de la Ynquisición", por lo cual solicitaba averiguación para obtener certificado de limpieza de sangre, lo que se inició dos días más tarde, obteniendo tal testimonio el $1^{\circ}$ de noviembre, firmado en la villa de Leiza. Tres años más tarde, el 7 de abril de 1634, el propio Juan de Segarra "el Mozo", en su nombre y en el de sus hermanas, en conformidad con tal documento y expresando su soltería y absoluta libertad, por no tener dada palabra de casamiento ni estar sujeto a ninguna orden religiosa, solicitó del teniente de Asistente de la ciudad de Sevilla su aceptación, porque "a mi derecho y de las dichas mis hermanas conbiene probar y aberiguar". Era corriente en la época esta inquietud por demostrar ser cristiano viejo, requisito necesario para ingresar en determinadas cofradías, obtener cargos, o para iniciar expediente de hidalguía, en alguno de cuyos supuestos podría insertarse esa pretensión ${ }^{3}$.

Respecto a la vecindad de la familia, no se sabe cual fué el barrio elegido a su llegada a Sevilla, ya que la primera noticia recogida, de 1621, no lo señala, y así, por declaraciones de Juan de Segarra padre, en abril de 1625 residían en la collación de Santa Marina, en julio de 1626 en la del Salvador, donde bautizó a Teresa, en abril de 1629 nuevamente en Santa Marina, y en enero de 1631 en San Juan de la Palma, que es la última conocida.

Josefa, que casó con Jacinto de Valdés, llegó a darle una nieta, Juana Manuela de Valdés, de la que quedó como tutor y curador de sus bienes por fallecimiento de sus padres, según afirmó el 20 de mayo de 1651, en que dió poder a Francisco de Torres como procurador en todos sus negocios y, por extensión, en los relativos a la menor ${ }^{4}$.

\section{NOTICIAS PROFESIONALES}

Su primera obra importante conocida como constructor es la iglesia del convento sevillano de Santas Justa y Rufina, o de la Santísima Trinidad, que el 22 de marzo

2. LOPEZ MARTINEZ, Celestino: Testimonios para la biografía... ob.cit., p. 222.

3. LOPEZ MARTINEZ, Celestino: Arquitectos, escultores... ob.cit., pp. 187-188.

4. LOPEZ MARTINEZ, Celestino: Arquitectos, escultores... ob.cit., p. 189. 
de 1621 contrató junto al maestro mayor de la Ciudad Andrés de Oviedo, según trazas del maestro mayor de la Catedral Miguel de Zumárraga y del padre maestro fray Miguel de Peñalosa. Previo al derribo del antiguo edificio, para reaprovechar, debían desmontar retablos, reja, púlpito, lo que hubiere en el coro y las gradas del altar mayor. Nueve años más tarde la fábrica aún no estaba conclusa, ya que al parecer Segarra la dejó en manos de Oviedo en 1625, y éste, que había llevado hasta entonces el peso de la obra, cansado porque no le pagaban, la abandonó, retomando su construcción en abril de 1630 por 1.000 ducados, con nuevas condiciones de Zumárraga para la terminación de bóvedas, encalados, solerías, y otras cosas menores, y al parecer levantó la portada y torre que no se contemplaban en el proyecto ${ }^{5}$. La iglesia es de planta basilical de tres naves y amplio crucero, de alzado similar a la del Sagrario de la Catedral, con arcos formeros entre pilares a los que se adosan pilastras de orden gigante, con bóveda de cañón con lunetos y fajones parejos en la nave central, media naranja de anillo denticulado en el crucero, y coro en alto a los pies sobre arco rebajado.

Para la rama descalza de esa orden, el 22 de abril de 1625 contrató la construcción de la iglesia de su convento de la collación de San Ildefonso, entre las calles Campanas de los Descalzos y Dormitorio de los Descalzos, actuales Descalzos y Dormitorio, y plaza homónima, absorbida en la actualidad por la de Cristo de Burgos. Podemos suponer que el empeño que puso en ella le determinó a dejar la anterior, ya encauzada, en manos de su amigo Oviedo. Aquí salió como fiador el carpintero Juan Bautista de Medina, que suponemos se hizo cargo de las labores de su oficio, y aunque en las condiciones no se expresa quién es el autor, no parece probable fuese Segarra, dada su condición sólo de experto constructor y no de tracista. Por el contrario, apuntar como estaban en plena actividad por esas fechas Diego López Bueno y Miguel de Zumárraga, maestros mayores de fábricas del Arzobispado y de la Catedral respectivamente, a cualquiera de los cuales pudo recurrir la Orden dada su actividad para el estamento religioso, aunque nos inclinamos por el último por su relación profesional con la comunidad ${ }^{6}$. La iglesia, de pequeñas proporciones, era de nave única con crucero y tres capillas laterales sin rejas a cada lado, con falsas bóvedas de yeso que al exterior se cubrían con estructura de madera tejada, y como era habitual, coro en alto a los pies. En los laterales, entre las capillas, abrían dos puertas, la del muro del evangelio que comunicaba con el claustro, y la del lado de la epístola que salía a la calle de las Campanas, sobre la que se asentaba el órgano y que afortunadamente se conserva al igual que el muro de ese lado, portada adintelada de clara raigambre tardomanierista, de un sencillo apilastrado de enmarque y frontón curvo desventrado que cobija una inestable y enorme clave trapezoidal, mientras que a los pies se disponía la desaparecida portada principal, eje dinamizador de la recoleta plaza triangular a la que daba nombre. El convento, situado detrás de la iglesia, ocupando la manzana entre calles, era igualmente

5. LOPEZ MARTINEZ, Celestino: Arquitectos, escultores... ob.cit., pp. 122-125, 127.

6. LOPEZ MARTINEZ, Celestino: Arquitectos, escultores... ob.cit., pp. 185-186. 
pequeño, estrecho pero acomodado, con claustro de arquerías cerradas con tabiques, que para 1844 estaba transformado en casa de vecindad, al igual que otras construcciones conventuales ${ }^{7}$. Airosa, emergiendo a duras penas del caserío que la envuelve, se alza su hermosa torre, asentada sobre el muro de la epístola de la iglesia, hacia la calle Descalzos, de planta cuadrada de estilizada figura, donde se alcanza un acertado decorativismo, fruto de la combinación de la brillante azulejería que la envuelve y la complejidad de su estructura decreciente. Sobre pequeño banco, el primer cuerpo presenta disposición clásica, de un único vano de medio punto de marcada rosca e imposta entre parejas de pilastras toscanas, y remate de frontón triangular saliente, tras el cual se continúa el cuerpo y los trozos de pilastras originados sobre el entablamento, que se corona de múltiples jarros que envuelven el segundo cuerpo, liso y decreciente, en el que se levanta un tercero piramidal, que anclado por pequeños dados en los vértices, juega caprichosamente con las curvas y contracurvas, creando unas formas bulbosas que serán características en su producción. La azulejería, de color azul, se desarrolla en forma de paneles sobre el banco, en las pilastras cajeándolas con tondo central, en las enjutas, entablamentos, tímpano del frontón, y en el remate piramidal como finas cintas que marcan su peculiar figura.

El 4 de mayo de 1626, junto al albañil Juan Bernardo de Velasco, futuro maestro mayor del Alcázar y de la Lonja de Mercaderes, contrata la decoración arquitectónica de la iglesia sevillana del Colegio franciscano de San Buenaventura, según trazas y dibujos del pintor Francisco de Herrera, en concreto, "el adorno de la yesería, talla y escultura, enluzidos y asentar las bedrieras e los quadros de pintura en el sitio que les pertenesen", ajustando la manufactura en 25.000 reales. No era sino el punto final de la construcción del templo, trazado cuatro años antes por Diego López Bueno, y realizado por el propio Bernardo de Velasco y el carpintero Felipe Nieto ${ }^{8}$. Sobre una trama recuadrada, superpuesta al intradós de las bóvedas, con antecedentes en los de la Catedral de la mezquita de Córdoba, motivos geométricos y mixtilíneos, con sobrias cartelas rectangulares de orejeras y jugosos óvalos de guirnarldas para acoger las pinturas de Herrera el Viejo, se completan con gruesas tallas de hojarasca, seres angélicos y frutas, iniciando la magnífica tradición yesera que acuñará el Barroco Sevillano del XVII.

Su buen quehacer como constructor de iglesias conventuales, le avaló para que junto al albañil Antonio Rodríguez acordase el $1^{\circ}$ de febrero de 1627 la reedificación del convento femenino de la Limpia Concepción de Nuestra Señora, junto a la iglesia de San Juan de la Palma, trazada por Zumárraga y Diego Gómez. En ello emplearon dos años, pues la tenían conclusa para el 15 de marzo de 1629 , en que

7. GONZALEZ DE LEON, Félix: Noticia Artística, Histórica y curiosa de todos los edificios de Sevilla. Sevilla, 1844, pp. 30-31.

8. LOPEZ MARTINEZ, Celestino: Arquitectos, escultores... ob.cit., pp. 209-210. MARTINEZ RIPOLL, Antonio: La iglesia del Colegio de San Buenaventura (Estilo e iconografia). Sevilla, 1976, pp. 13-14, 25-29. PLEGUEZUELO HERNANDEZ, Alfonso: Diego López Bueno ensamblador, escultor y arquitecto. Sevilla, 1994, pp. 54-55. 
fué tasada por el maestro de fábricas del Arzobispado Cristóbal Ortiz, por el de la Lonja Marcos de Soto, y por Juan Bernardo de Velasco, que llegaron al acuerdo de cifrarla en 56.106 reales, de los cuales 51.806 eran por su fábrica, 3.300 por la portada, y 1.000 por los derribos, cantidad a la que había que bajar los 38.510 que ya habían cobrado. Al mes siguiente Segarra otorgó carta dotal para el ingreso en el convento de su hija María ${ }^{9}$. La iglesia, que era de mediano tamaño, de cajón de nave única con el interior dividido por reja para formar los coros, cubierta con bóveda de cañón, y capilla mayor diferenciada por potente arco toral sobre el que se elevaba una media naranja, quedó arruinada por un pequeño terremoto en agosto de 1840 , que la dejó en alberca ${ }^{10}$. El convento, entre la plaza de Menjíbar y la calle de la Feria, ha subsistido hasta casi nuestros día, transformado en casa de vecindad.

Si hasta esos momento se nomina maestro albañil, a partir de 1629 , tras su elección como alcalde alarife de albañilería, que solía ser cuatrianual e implicaba el reconocimiento del gremio, su espíritu se envanecerá con justo orgullo, y empezará a titularse arquitecto, maestro albañil y alcalde alarife, que se constata lo era en 1631 y 1635 . Coincide con esos años, concretamente 1631 y 1634, los dos confusos documentos en que aparece su hijo, adoptando iguales rangos en las solicitudes de certificados de limpieza de sangre.

En 1629 trabajó en la casa del conde de Castellar, en la calle homónima, por lo que cobró 5.752 reales el 27 de enero de 1631 por tasación de Cristóbal Ortiz ${ }^{11}$. Como alarife, intervino ese año de 1631 en el largo pleito que mantenía el carpintero y tratadista Diego López de Arenas con el convento de jerónimas de Santa Paula, de Sevilla, por la compra a tributo perpétuo de una casa en la calle de la Correría, al considerar su precio excesivo, aviniéndose junto con otros alarifes consultados al precio de 3.000 maravedies anuales ${ }^{12}$.

Aunque tradicionalmente se le atribuía el claustro grande del monasterio sevillano de San Clemente, desde que así lo apuntara en 1944 el prof. Hernández Díaz, apoyándose en una inscripción de su terminación en 1632, y que por esas fechas, en 1633, era "maestro mayor de los monasterios y conventos de la jurisdicción hordinaria deste Arzobispado", nuevas investigaciones han documentado como en 1617 estaban construídas dos de sus cuatro crujías, y como en ese año se dieron condiciones por Zumárraga y López Bueno para erigir una tercera, que contrató el albañil Diego Gómez, por lo que solo podría asignársele la conclusión definitiva de ese espacio con la cuarta ${ }^{13}$.

9. LOPEZ MARTINEZ, Celestino: Arquitectos, escultores... ob.cit., p. 186. FRAGA IRIBARNE, $\mathrm{M}^{\mathrm{a}}$ Luisa: Conventos femeninos desaparecidos. Arquitectura religiosa perdida durante el siglo XIX en Sevilla. Sevilla, 1993, pp. 192-195, 198-200.

10. GONZALEZ DE LEON, Félix: Noticia Artística,... ob.cit., pp. 215-216, 607.

11. LOPEZ MARTINEZ, Celestino: Arquitectos, escultores... ob.cit., p 187.

12. TOAJAS ROGER, $M^{2}$ Angeles: Diego López de Arenas. Carpintero, alarife y tratadista en la Sevilla del siglo XVII. Sevilla, 1989, pp. 179-182.

13. HERNANDEZ DIAZ, José: El Claustro grande del monasterio sevillano de San Clemente. "Archivo Hispalense", Sevilla, 1944, t. II, pp. 61-64. PLEGUEZUELO HERNANDEZ, Alfonso: Diego López Bueno... ob.cit., p. 57. 
También en 1632, nuevamente con Antonio Rodríguez, concierta el 8 de octubre con el convento femenino dominico de Santa María la Real, de Sevilla, la labra de su iglesia, en lo que emplearon unos ocho años. El 23 de noviembre de 1635, con la obra ya bastante avanzada, otorgaron carta de pago a su mayordomo Francisco Hurtado Niño por 22.000 reales a cuenta de lo que estaban haciendo, aunque finalmente, el 3 de abril de 1640, el citado Rodríguez la abandonó, traspasándole por escritura "todo lo que le pertenece" ${ }^{14}$. En la calle ancha de San Vicente, su iglesia es una de las mayores de las del tipo conventual de nave única, de cañón cubierto por estructura de madera, dividido por rejas para formar los coros, y capilla mayor separada por el correspondiente arco toral ${ }^{15}$.

Como maestro mayor de los monasterios de monjas, en funciones de alarife, el 20 de octubre de 1633 visitó unas casas pertenecientes a dicha orden en la calle de la Cruz de los Talabarteros -Alvarez Quintero-, esquina a la calleja de Martín Morales, y el 24 de enero de 1634, otras de San Clemente en una callejuela sin salida junto a la de Jamerdana. Y con el mismo cargo en el Hospital de la Sangre, para el que trabajó al parecer fundamentalmente como alarife, el 21 de mayo de 1637 junto a su colaborador allí el carpintero Francisco Rodríguez, midió y apreció el Mesón del Sol, en la plazuela de la Paja -actual Ponce de León-. En esta faceta hay que encuadrar igualmente otras intervenciones, en alguna de las cuales acometió personalmente la obra, como en unas casas que el pintor Francisco Pacheco tenía arrendadas del Hospital del Amor de Dios ${ }^{16}$.

Su vinculación con la maestría mayor de la ciudad de Sevilla se produjo durante la ocupación del cargo por Marcos de Soto, que le dejó en su lugar como persona de su confianza cuando tuvo que ausentarse a instancias del duque de Medina Sidonia para inspeccionar las fortificaciones de la ciudad de Cádiz. Ese primer paso, simple, era fundamental para la pretensión de estos maestros a la ocupación de la plaza en cuanto vacase, práctica que hemos constatado fué habitual durante todo el XVII. Y así fué como, tras la muerte de Soto a finales de julio de 1635, el mismo día de su entierro, el domingo 29, se recibió en cabildo municipal su petición para que le fuese concedida, e inmediatamente la de otros tres, el $1^{\circ}$ de agosto la del albañil Melchor de la Vega, y el 3 la del futuro maestro de fábricas del Arzobispado Diego Gómez y la del arquitecto catedralicio Pedro Sánchez Falconete, que igualmente expuso como hacía diez años que servía a la ciudad como sustituto de Andrés de Oviedo. En su detallada exposición, Segarra se titula como acostumbraba por esos años "maestro arquitecto y de albañilería", enumerando los servicios prestados satisfactoriamente en la ausencia de Soto, y como entre su bagaje se encontraba un conjunto muy importante de construcciones, "y del dicho mi arte, en que como es notorio las obras que en esta ciudad e hecho, que son la del colegio de San Buena-

14. LOPEZ MARTINEZ, Celestino: Arquitectos, escultores... ob.cit., pp. 188-189. Desde Martínez Montañes hasta Pedro Roldan. Sevilla, 1932, p. 166.

15. GONZALEZ DE LEON, Félix: Noticia Artística... ob.cit., pp. 479-480.

16. LOPEZ MARTINEZ, Celestino: Arquitectos, escultores... ob.cit., pp. 188-189. Retablos y esculturas de traza sevillana. Sevilla, 1928, p. 93. 
ventura, su templo, y el de las monjas de la Concesión de San Juan de la.Palma, y el de los padres trinitarios descalços de la Binatería, y el de las monjas de Santa María la Real, que al presente estoy labrando, y otras muchas dentro y fuera desta ciudad; que por ser notorio y no cansar a $\mathrm{V}^{\mathbf{a}} \mathrm{S}^{\mathbf{a}}$ no lo refiero". Como vemos, casi. todas las comentadas hasta ahora, ya que solo olvida la iglesia de la Santísima Trinidad. Su petición y la de los otros fué estudiada en el cabildo de 3 de agosto, presidido por el Asistente García Sarmiento de Sotomayor, conde de Salvatierra, que acordó, como era costumbre, la elección por votación secreta, de la que salió como nuevo arquitecto municipal Pedro Sánchez Falconete con 25 votos, incluído el del Asistente que fué su valedor, frente a los 22 de Diego Gómez, 1 para Melchor de la Vega, y los 5 que obtuvo Segarra ${ }^{17}$.

A pesar de este revés no se desanimó, ni mudó su relación de amistad con el recién elegido, sino que muy al contrario la reforzó con el tiempo, al darse cuenta del nuevo espíritu que representaba para la arquitectura sevillana, al propugnar el cambio hacia las nuevas formas barrocas a través de la dinamización de los espacios por el empleo de la ornamentación. Y si hasta ahora su personalidad se había desenvuelto entre figuras como Martínez Montañés, Zumárraga, Andrés de Oviedo, Juan Bernardo de Velasco o Antonio Rodríguez, todos ellos convencidos exponentes de la estética Protobarroca, ahora, en la cima de su notoriedad, se enriquece al entrar en contacto con los círculos profesionales y de amistad creados en torno a Falconete, dando lugar a una interesante influencia mutua, en donde las formas en las que uno acaba sirven al otro de partida.

Esa amistad propició que, cuando Falconete sufrió un aparatoso accidente con un caballo en febrero de 1648 , de regreso de una inspección de las aguas de la Alameda, que le mantuvo varias semanas apartado de sus cargos de arquitecto del Ayuntamiento, Lonja de Mercaderes y Catedral, le dejara como sustituto en las tres instituciones, sin duda, con el buen ánimo de que esa suplencia le sirviese en el futuro para aspirar a alguna de las plazas u a otras por el prestigio que le daría, y que en el caso del municipio venía además avalado por su antiguo trabajo en la ausencia de Soto, que implicaba se guardase con él una cierta relación laboral. Aunque el tiempo de esa actividad fué escaso, poco más de un mes, desde fines de febrero hasta mediados de abril, fueron diversas sus intervenciones.

En las referentes al municipio, el propio Segarra en la petición que de forma inmediata elevó para obtener justa compensación económica, leída en el cabildo del 24 de abril, y en la que se titula "maestro de obras", señala pormenorizadamente todas ellas, "e hecho el oficio de maestro mayor por la enfermedad y ausençia de Pedro Sánchez Falconete, maestro mayor de $\mathrm{V}^{\mathrm{a}} \mathrm{S}^{\mathrm{a}}$, acudiendo a todas las ocaciones que se an ofrecido de obras públicas y vistas de ellas, que por acuerdo de $\mathrm{V}^{\mathrm{a}} \mathrm{S}^{\mathrm{a}}$ se

17. LOPEZ MARTINEZ, Celestino: Arquitectos, escultores... ob.cit., pp. 179-180, 189. Maestros Mayores del Concejo Hispalense. En Documentos para la $\mathrm{H}^{\mathrm{a}}$ del Arte en Andalucía, T. I, p. 141. CRUZ ISIDORO, Fernando: El arquitecto sevillano Pedro Sánchez Falconete. Sevilla, 1991, pp. 57-58. MORALES MARTINEZ, Alfredo: Sobre Pedro Sanchez Falconete, maestro mayor del Ayuntamiento de Sevilla. "Archivo Hispalense", ${ }^{\circ}$ 229, Sevilla, 1992, pp. 133-134. 
me a mandado hacer acompañando a el señor procurador mayor, y e asistido continuadamente todo el tiempo que duró el hacer el cadaanso (sic) para el día del auto de la fe, y reparos que se devieron hacer en la plaça de San Francisco, y repartimientos de sitios en el arenal, y visitas de cameçerías y matadero, y visita de el Santuario de la Cruz de el Campo, y siempre estoy y estaré a el servicio de $\mathrm{V}^{\mathbf{a}} \mathrm{S}^{\mathrm{a}}$, y más me mandare, sin que por lo referido se me aya hecho merçed ninguna", en vista de lo cual se ordenó el libramiento por vía de gratificación de la considerable cantidad de 40 ducados ${ }^{18}$. Pero veamos esas intervenciones con detenimiento.

Con mucho, la de mayor interés fué la traza y confección del cadalso para el auto de fe celebrado el sábado 28 de marzo en la plaza de San Francisco, por lo que tiene de relevante ese tipo de arquitectura efímera que se desenvuelve en un tono de barroca teatralidad tan del gusto de la sociedad hispana, aunque la motivación no pueda ser más oscura y siniestra. En el archivo catedralicio se conserva detallada relación de los sucesos y de la compleja escenografía con que se desarrollaron. Unas semanas antes, el domingo 8 de ese mes, se publicó el auto general por todos los familiares, secretarios y ministros de la Inquisición que, a caballo, y presididos por su alguacil mayor $\mathrm{D}$. Juan de Saavedra, lo pregonaron a los cuatro vientos de la ciudad. Un día antes del suceso, el viernes 27 , a viva voz se prohibió que nadie portara espada, con la salvedad de los criados de los señores. En el día fatídico se formó solemne procesión desde el Castillo inquisitorial de Triana hasta la plaza de San Francisco, pasando por la puerta del Arenal y calles de la Mar y Génova, formada por los miembros en pleno del Santo Oficio que portaban velas de a libra y media, y entre ellos, la Cruz de la Fe en unas andas cubiertas de color negro, los penitenciados, uno que sería quemado, uná carroza portando veintiuna estatuas símbolo de ausentes que también servirían de pasto a las llamas, otra con un arca pequeño conteniendo el proceso, el palio carmesí de la Santa Iglesia, los calificadores y consultores del Santo Oficio, clérigos de diversas órdenes, y cerrando D. Juan de Saavedra con el estandarte de la Hdad. de San Pedro Mártir, tamizada la marcha por el fúnebre tañido de las campanas de la Giralda a medio tono. Con suficiente antelación, Segarra había levantado arrimada al ayuntamiento la estructura efímera lignaria acostumbrada, un palenque o tablado para el tribunal y otro para los reos, en el que había un altar morado donde se colocó la cruz. En los "corredores" del cabildo, como eran conocidas las dobles galerías italianizantes abiertas a la plaza que Hernán Ruiz II adosó al edificio plateresco, formó cuatro gradas corridas, desde la puerta de entrada hasta la pared frontera, todas alfombradas, en medio de la primera y principal el sitial carmesí de la Inquisición para un santo Cristo crucificado bordado de oro, debajo se sentaron esos señores con un bufete con sobremesa y campanillas, a su lado, a la izquierda, el canónigo D. Pedro Osorio, ordinario de Cádiz, y los munícipes, y a la derecha, la Audiencia Real. Para relatar la causa se erigieron dos púlpitos de vara y media, que bajaban por dos gradas a un puente o pasarela donde se hizo una tarima de tres gradas de a 2 varas, a donde se subió a los

18. Archivo Municipal de Sevilla, secc. II Contaduría, Acuerdos para librar, carp. 22 (1648) nº 40. 
reos para que escuchasen el proceso. Este puente de madera se unía a un tablado frontero en forma de media naranja con cuatro gradillas para los familiares de la Inquisición, comisarios del arzobispado, colegial del Salvador y clerecía. A su izquierda otro del mismo alto, que llegó hasta la esquina "de la casa de los portales", y uno para las órdenes femeninas. Además se formaron varias gradas fronteras al puente, alfombradas y forrados los pies derechos con terciopelo carmesí, formando puertas y ventanas, y colgáronse telas verdes y carmesíes desde lo alto de la azotea de las Casas Capitulares hasta caer sobre ellos y los antepechos del tablado, al que se accedía por una escalera arrimada a la cornisa del edificio ${ }^{19}$.

La inspección que llevó a cabo en el Templete de la Cruz del Campo, humilladero mudéjar erigido en 1482 por el Asistente Diego de Merlo para conmemorar la reconstrucción del acueducto que traía agua fresca a la ciudad, conocido como Caños de Carmona, determinó una delicada restauración de su fábrica de ladrillo, de planta cuadrada abierta en cada frente por arco apuntado sobre pilares, cubierta con bóveda octogonal, y rematada con antepecho ciego de merlonaje escalonado. Sin duda, debe ser la que recoge Gestoso, del 4 de abril de ese año de 1648, en que se libraron al alcalde mayor Pedro Caballero de Illescas 500 reales para reforzar uno de los estribos, rehacer las gradas, resanar la bóveda y desasolvar las atarjeas que vertían las llovedizas ${ }^{20}$.

Para concluir este apartado, ya que de sus visitas a las diferentes carnicerías y al Matadero no hemos localizado ninguna intervención en el Archivo Municipal, por lo que suponemos no dió lugar a ningún tipo de obra, señalar como junto al cañero Miguel de Molina asistió en repetidos días a la limpieza general o "mondo real", efectuada en los citados Caños por Pedro Clavero, desde la Puerta de Carmona hasta la mina de agua en Alcalá de Guadaíra, para comprobar si las condiciones dictadas para su arreglo por el maestro mayor Falconete se cumplían, como fueron la limpieza de las tablas, las lumbreras y la mina por dentro y fuera, estaquear los portillos y tapar los sudaderos ${ }^{21}$.

De su labor en la Lonja de Mercaderes ha quedado memoria por un informe que rubricó el 28 de febrero de 1648, en el que afirma "Yo, Juan de Segarra, maestro de albañilería y que hago las ausencias de Pedro Sánchez Falconete, maestro mayor de la Ciudad y de la Lonja, con asistencia del contador Juan Antonio de Ybarra, secretario y que haze el oficio de veedor del Consulado y fábrica...", haber visto y medido la pared del corralillo de la Lonja que lindaba con el Colegio de Santo Tomás, caído por aquellas fechas por las copiosas lluvias, ordenándosele su reconstrucción, estimando como su superfie, de 20 tapias, en las que se incluían los cimientos, pared y caballete, debía remunerarse a 13 reales cada una, y como debían echarse tres hiladas de ladrillo para que cargasen las tres tapias de alto, con refuerzos laterales de rafas o machones, aprovechando el pedazo de pared que aún quedaba. De la obra

19. Archivo de la Catedral de Sevilla, secc. Varios, caja 59-60, doc. 59 (1), fols. 209-214 vto.

20. GESTOSO Y PEREZ, José: Sevilla Monumental y Artística. T. W, Sevilla, 1892, reed. facs. 1984, pp. 537-542.

21. Archivo Municipal de Sevilla, secc. II Contaduría, Acuerdos para librar, carp. $22(1648) n^{\circ} 109$. 
se encargó el albañil Juan Rodríguez, que la contrató ese día por 260 reales, citándose a Segarra en ese documento como "theniente de maestro mayor de albañilería de la Ciudad" 22 . Como vemos, la idea que animaba esa colaboración había surtido pleno efecto, pues aunque Segarra en ninguna ocasión se nombra como tal, así era considerado en el ambiente de su profesión y entre los estamentos para los que trabajaba, es decir, como el segundo arquitecto municipal y previsible titular en un futuro, manteniendo abierta esa espectativa que anhelaba desde su sustitución de Marcos de Soto, hacía casi tres lustros, y que nunca alcanzaría, por cuanto Falconete ocupó la plaza treinta y un años, hasta su defunción en 1666, cuando Segarra llevaba ya varios muerto.

Aunque no tenemos referencia de ninguna intervención en la Catedral, creemos que igualmente sustituyó a Falconete en su convalecencia, ya que allí no contaba tampoco con ayudante. Para ello no solo nos basamos en lo comentado hasta ahora, sino en el hecho de que un año más tarde, el 9 de julio de 1649, el cabildo catedralicio lo nombró su sustituto como alarife visitador de sus posesiones inmuebles: "Este día mandó el cavildo que Pedro Sánchez Falconete, alarife, vaia a las visitas de casas quando los señores visitadores le mandasen, y si no fuese llamado y citado, vaia en su lugar Juan de Cegarra", asunto sobremanera delicado para esa institución, en que ponía máximo cuidado por intervenir la apreciación monetaria y las reformas de las viviendas a que los inquilinos estaban obligados, que se reflejaban en las ${ }_{4}$ escrituras de concierto de arrendamiento, y que no hubiese puesto en sus manos si no contara con el referentè previo de su honradez y buen hacer, ejercido probablemente de forma puntual desde aquellas fechas, y que ahora toma carácter oficial ${ }^{23}$..

No sabemos en que año falleció. La última referencia documental conocida es la ya citada de mayo de 1651, en el que otorgó poder como procurador a Juan Francisco de Torres, aunque es interesante señalar como la plaza que ocupaba en la Catedral vacó en 1657, por cuanto el 29 de octubre se concedió al también colaborador de Falconete, Pedro López del Valle, por lo que no es descartado tomar esa última fecha como hito a tomar en cuenta ${ }^{24}$.

22. Archivo General de Indias, secc. Consulados, leg. 1.139, $\mathrm{n}^{\circ} 6$, fols. $40,41$.

23. Archivo de la Catedral de Sevilla, Actas Capitulares de los años de 1649-50, $\mathrm{n}^{\circ} 60$, fol. 85 . CRUZ ISIDORO, Fernando: El arquitecto sevillano Pedro Sánchez Falconete. Ob. cit., pp. 26, 60, 74. Pareceres y aprecios en la Sevilla del segundo tercio del siglo XVII. "Atrio", $\mathrm{n}^{\circ} 3$, Sevilla, 1991, pp. 42,47 (doc. $n^{\circ} 3$ ).

24. Archivo de la Catedral de Sevilla, Actas Capitulares de los años de 1657-58, $\mathrm{n}^{\circ} 61$, fols. 58 vto., 59. 


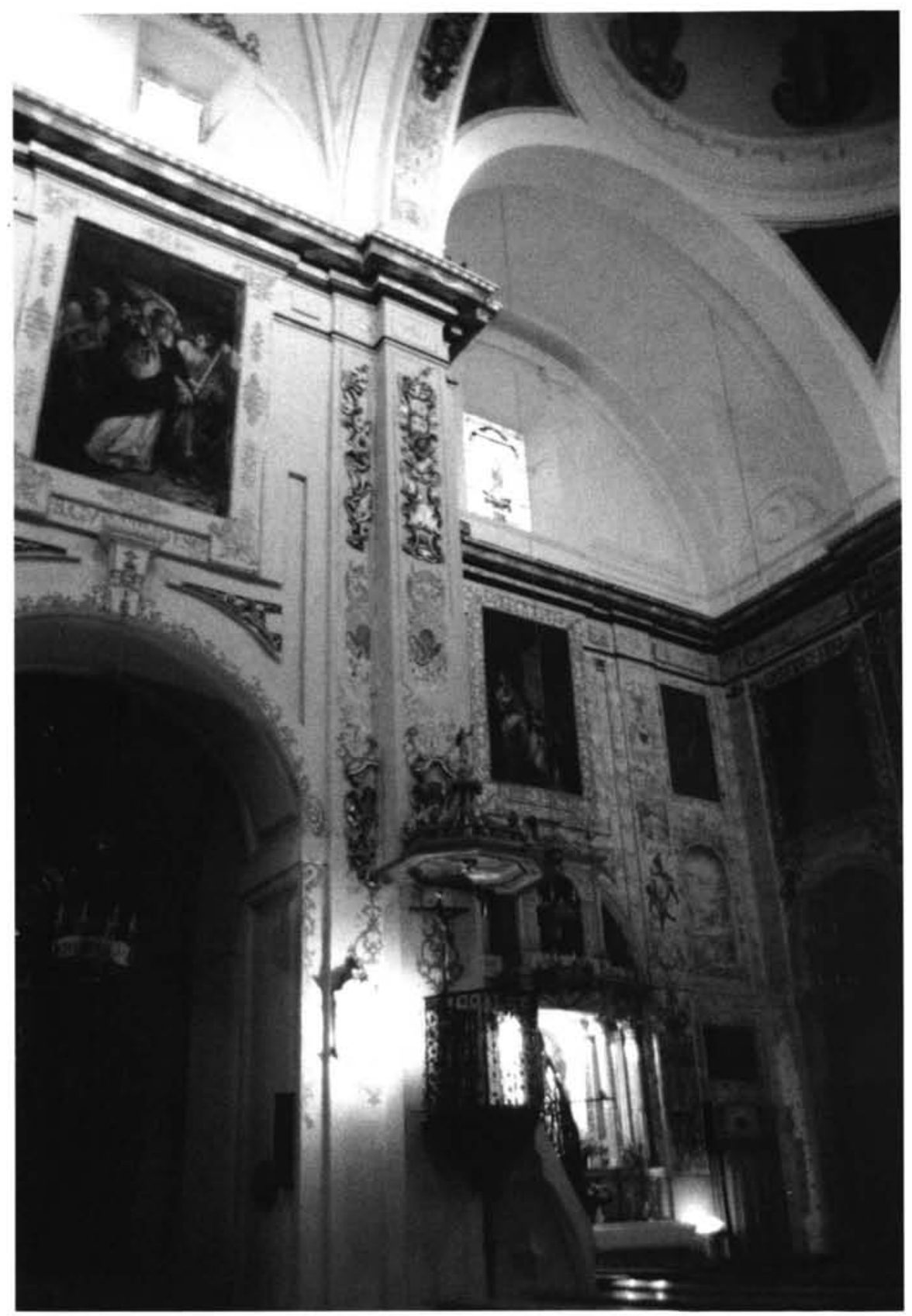

Lám. 1

Interior de la iglesia del extinto convento de Santas Justa y Rufina de los Trinitarios calzados, hoy iglesia de la Trinidad de la Congregación de Salesianos. 


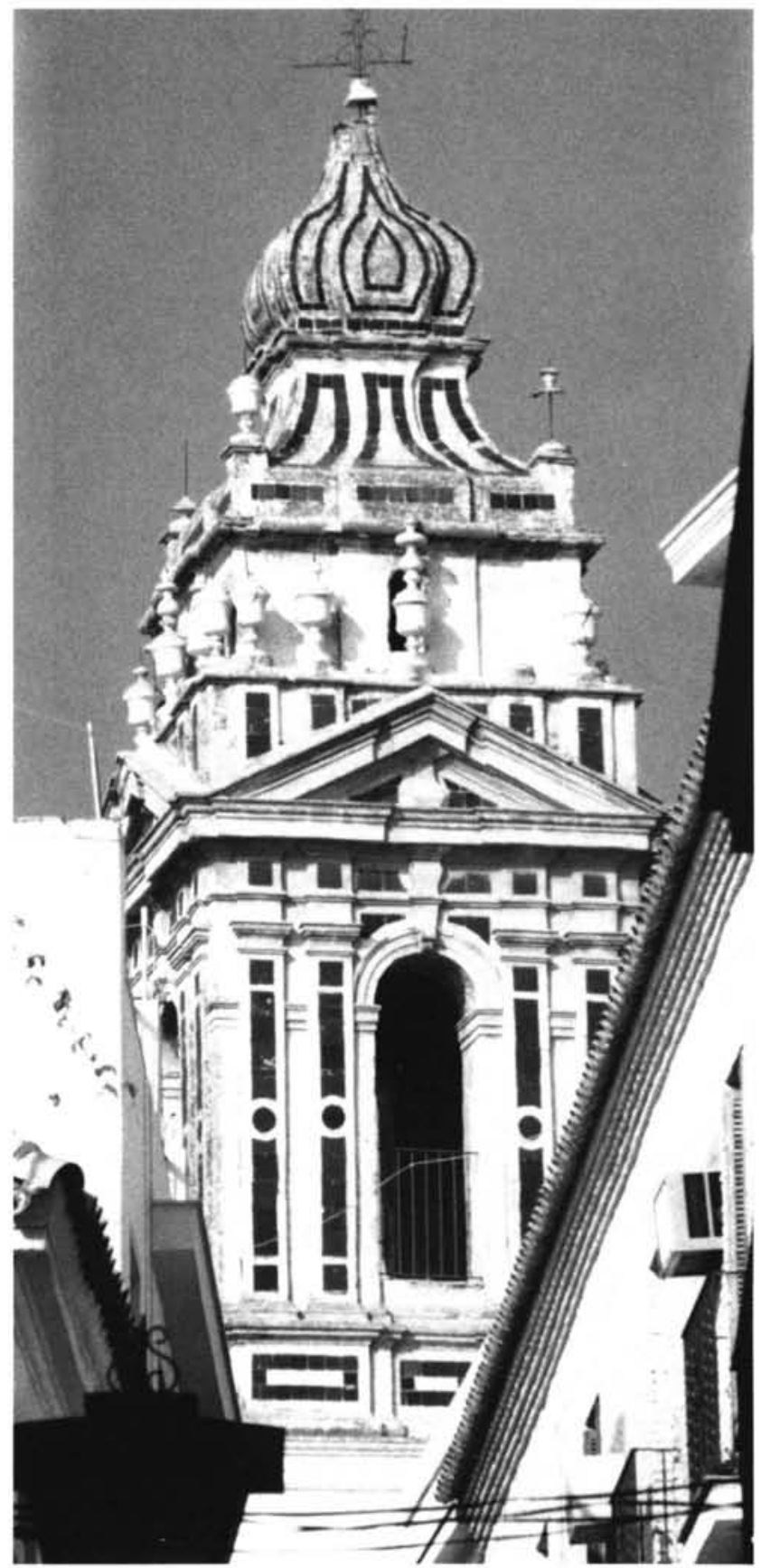

Lám. 2

Torre de la iglesia del extinto convento de los Trinitarios descalzos. 